\title{
Insights on Blood Cytokines Production under Different In Vitro Mycobacterial Antigens in Tuberculosis Intestinal Parasites Co Infected Patients
}

\author{
Renan Jeremias da Silva1, Fernanda C. Q. Mello², Janaína A. Leung², \\ Antonio Henrique Almeida de Moraes Neto ${ }^{3}$, Leila de Souza Fonseca ${ }^{2}$, Helio Ribeiro de Siqueira ${ }^{4}$, \\ Health Care Victor Vala and CSEGSF Team5, Maria Helena Féres Saad ${ }^{*}$ * \\ ${ }^{1}$ Laboratory of Cellular Microbiology, Oswaldo Cruz Institute (IOC), Fiocruz, Rio de Janeiro, Brazil \\ ${ }^{2}$ Federal University of Rio de Janeiro, Clementino Fraga Filho Hospital, Rio de Janeiro, RJ, Brazil \\ ${ }^{3}$ Laboratory of Innovations in Therapies, Teaching and Bioproducts, Oswaldo Cruz Institute (IOC), Fiocruz, Rio de Janeiro, Brazil \\ ${ }^{4}$ Rio de Janeiro State University, Pedro Ernesto Hospital, Rio de Janeiro, Brazil \\ ${ }^{5}$ Victor Vala Family Clinic and Health Care-School Germano Silval Farias (CSEGSF), ENSP/Fiocruz, Rio de Janeiro, Brazil \\ Email: *saad@ioc.fiocruz.br
}

How to cite this paper: Silva, R.J., Mello, F.C.Q., Leung, J.A., Moraes Neto, A.H.A., Fonseca, L.S., Siqueira, H.R., Health Care Victor Vala and CSEGSF Team and Saad, M.H.F. (2018) Insights on Blood Cytokines Production under Different In Vitro Mycobacterial Antigens in Tuberculosis Intestinal Parasites Co Infected Patients. Advances in Microbiology, 8, 161-174. https://doi.org/10.4236/aim.2018.83011

Received: January 3, 2018

Accepted: March 18, 2018

Published: March 21, 2018

Copyright (c) 2018 by authors and Scientific Research Publishing Inc. This work is licensed under the Creative Commons Attribution International License (CC BY 4.0).

http://creativecommons.org/licenses/by/4.0/ (c) (i) Open Access

\begin{abstract}
Background: The concomitant presence of intestinal parasite infections (IP) and tuberculosis (TB) has relevance. M. tuberculosis immune response is associated with type $1 \mathrm{~T}$ helper cell (Th1) while IP is associated with type Th2 cell. However, there are several contradictory reports on cytokine production under coinfection and this could be in association to the mycobacterial antigens used in the studies. Aim: To get insight into the effects of different $M$. tuberculosis-specific antigens (ESAT-6/CFP-10 and $38 \mathrm{kDa} / \mathrm{CFP}-10$ ) in generating of appropriate cytokines on peripheral blood mononuclear cells of IPTB co infected patients. Method: ELISA assessed IFN- $\gamma$ and other 16 cytokines production and plasm IgE. In 18 months, we documented demographic, economic, clinical characteristics and IP frequency in individuals from Brazil. Results: An overall 10/35 (28.5\%) were IPTB co infected and 40/76 (52.6\%; p $=0.024)$ asymptomatic intestinal parasite infected community controls (IPCC). Endolimax nana (40\%) and Entamoeba coli (22\%), were the most nonpathogenic protozoan identified and Entamoeba histolytica, Giardia intestinalis, Ascaris lumbricoides and Strongyloides stercoralis were the pathogenic species $(40 \%)$. IgE was higher in IPCC $(\mathrm{p}=0.036)$. Cytokine profiles were significantly biased toward a Th2 type IL-5 $(\mathrm{p}=0.001)$ and IL-13 $(\mathrm{p}=0.033)$, pro-inflammatory GM-CSF ( $\mathrm{p}=0.019)$ and borderline lower IL- $1 \beta$ in IPTB, all associated with ESAT-6/CFP-10, while IL-7 was borderline lower, but 38
\end{abstract}


$\mathrm{kDa} / \mathrm{CFP}-10$ associated; as well as IL-8 higher $(\mathrm{p}<0.049)$ vs CC/IPCC. The TB/IPTB IFN- $\gamma$ levels were similar to both antigens stimuli ( $\mathrm{p} \geq 0.208$ ). Con-

clusion: Therefore, coincident IPTB coinfection did not exert a significant inhibitory effect in IFN- $\gamma$ production in response to either of the two antigens, but the partial discrepancy in Th1/Th2 response, is associated with the antigen priming cells.

\section{Keywords}

Mycobacterium tuberculosis, Intestinal Parasites, Mycobacterial Antigens, IgE, Cytokines

\section{Introduction}

Mycobacterium tuberculosis (Mtb) is a facultative intracellular pathogen whose host immune response plays a vital role in infection outcome. The immune control of this infection is dependent upon the cellular immune response, mediated predominantly by CD4+ and CD8+ cells, with T helper (Th) 1 cytokine production, as IFN- $\gamma$, the major component in stimulation/activation of macrophages in infection control and bacillus elimination [1].

Helminths and other parasites, as well as bacteria, fungi and some viruses, perpetrate neglected tropical diseases that affect low-income populations [2]. Recent studies suggest an overlap of $\mathrm{TB}$ and parasite endemic regions, which can result in coinfection [3]. The chronic helminth infections are associated with Th2 immune response [4], and TB is dependent to effector response of Th1 cell. Studies have reported, in TB/Helminth co infected patients, a decrease in the production of IL-2 and INF- $\gamma$ [5] [6] [7] or an increase of IL-6, IL-10 and TNF- $\alpha$ [8] [9] [10] [11]. In a study with CBA mice, with a serious form of schistosomiasis, there were significant reductions in IL-17, INF- $\gamma$, TNF- $\alpha$, IL-23, IL-6 and IL- $1 \beta$ levels with increases of IL- 4 , IL- 5 , IL- 10 and TNF- $\beta$ [12]. On the other hand, despite other reports of decreases in INF- $\gamma$ levels with increases in IL-10, IL-4 and IL-5 were immeasurable [13]. Observations in culture supernatants of whole blood stimulated with PPD (purified protein derivative) described decreased IFN- $\gamma$ production in $\mathrm{TB} /$ helminth co infected individuals vaccinated with BCG (Bacille Calmette Guerin) [14]. However, other authors have reported that coinfection does not affect IFN- $\gamma$ production to Mtb infection [15] [16] [17]. It is possible that different immunological findings linked to the recognition of different mycobacterial antigens use in those studies. Henceforth, in order to get insight that specific mycobacterial antigens may generate different Th1/Th2 pattern, we measured plasm IgE and the principal cytokines induced by peripheral blood mononuclear cells (PBMC) of IP co infected donors and tuberculous patients. They were stimulated with two specific-Mtb antigens 38 $\mathrm{kDa} / \mathrm{CFP}-10$ and ESAT-6/CFP-10; both attractive alternatives for TB/infection diagnosis by interferon gamma release assay [18] [19] [20]. 


\section{Methods}

\subsection{Study Participants and Ethical Statement}

From June 2011 to December 2012, blood and one-stool samples were collected from control and TB patients. All attended at Clementino Fraga Filho University Hospital, Pedro Ernesto University Hospital, School Center Germano Sinval Farias/FIOCRUZ, and Family Clinic Victor Valla (CFVV) seated in Manguinhos Complex, an urban slum area with high TB incidence rate, all in Rio de Janeiro, Brazil. TB diagnostic followed the World Health Organization (WHO) criteria [21]. A consent form was required prior to enrollment and collect samples. The feces were examined by Lutz method [22]. All participants were $\geq 18$ years old, negative serology for HIV. Patients groups included TB patients and asymptomatic community control positive for intestinal parasitism referred as IPTB and IPCC, respectively, tuberculous patients (TB) and healthy community controls (CC). Survey of participant socio-environment conditions were obtained on a structured questionnaire on age, education, income, domicile characteristic, drinking water and garbage collection.

The National Ethical Committee for Human Research n. 548/10 approved the study and all participants signed a written informed consent before samples donation.

\subsection{Antigens}

The mycobacterial recombinant antigens early secretory antigenic target 6 (ESAT-6) and $38 \mathrm{kDa}$, also known as phosphate-specific transporter-1 (PstS1), were separately combined with $10 \mathrm{kDa}$ culture filtrate protein (CFP-10). All kindly donated by LIONEX GmbH (Braunschweig, Germany) and used at a final concentration of $5 \mu \mathrm{g} / \mathrm{mL}$, as well as Concanavalin A mitogen (ConA; Sigma, St. Louis, MO) [18].

\subsection{Peripheral Blood Mononuclear Cells (PBMC) In Vitro Culture}

PBMCs were isolated and cultured as previously described [18]. Briefly, PBMCs were obtained from heparinized venous blood by Ficoll-Hypaque density gradient centrifugation (GE Healthcare, Uppsala, Sweden). For the cell culture, $1 \times$ $10^{6}$ cells $/ \mathrm{ml}$ were plated in triplicate in 96-well, flat-bottom microtiter plates (Nunc, Swedesboro, NJ) in $300 \mu \mathrm{l}$ of RPMI 1640-HEPES supplemented with 20\% autologous serum and $100 \mathrm{U} / \mathrm{ml}$ penicillin and streptomycin (Gibco, Paisley, United Kingdom) in the presence or absence of the antigens. The plates were placed at $37^{\circ} \mathrm{C}$ in a humidified $5 \% \mathrm{CO}_{2}$ incubator for 5 days. Culture supernatants $\left(200 \mu \mathrm{l} /\right.$ well for each triplicate) were pooled and then stored at $-70^{\circ} \mathrm{C}$ for further cytokine quantification.

\subsection{Cytokines Detection}

The IFN- $\gamma$ was determined with the commercial kit based on immunoenzyme assay (ELISA), DuoSet IFN- $\gamma$ kit (R\&D, USA). Cut off was previously estab- 
lished by a receiver operating characteristic (ROC) curve as $100 \mathrm{pg} / \mathrm{ml}$ [18]. The other 16 cytokines/chemokines levels were assessed with the commercially available Luminex-based technology BioPlex Pro $^{\text {TM }}$ multiple human cytokine assay system (Bio-Rad Hercules, CA, USA), according to manufacturer's instructions. It was included the IL- $1 \beta$ (of IL- 1 family), IL- 2 and TNF- $\alpha$, of the type 1 response, IL-4, IL-5 and IL-13, of the type 2 Th cell response, IL-17A, one of the type $17 \mathrm{~T}$ cell response, regulatory IL-10, pro-inflammatory IL-6, IL-12p70 and GM-CSF and chemokines IL-8, CCL-2 (MCP-1), CCL-4 (MIP-1 $\beta$ ), G-CSF and the IL-7.

\subsection{Quantification of IgE}

Plasm IgE levels were measured by AccuBindTM ELISA Microwells Immunoglobulin E (IgE) test system (Monobind, Inc., Lake Forest, CA), according to manufacturer's instructions.

\subsection{Statistical Analysis}

Statistical analyzes were performed on Statistical Package for Social Sciences (SPSS) software, v. 17.0; differences of means with $\mathrm{p} \leq 0.05$ was considered significant. The nonparametric test was used to analyze significant differences when comparing the groups (Kruskal Wallis) and pairwise comparisons (MannWhitney).

\section{Results}

\subsection{Characteristics of Study Participants and Frequency of IP Infection}

As showed in Table 1, majority TB patients were of the pulmonary clinical form (74.3\%), negative acid-fast bacilli smear (65.5\%), non-smokers (71.4\%) and untreated $(19 / 35,54.2 \%)$ or treated less than three months $(8 / 35,22.8 \%)$. TB patients (37.1\%) lives in precarious domiciles compared to CC $(9.2 \%, p=0.003)$. Among IPTB the smoking habit was higher $(\mathrm{p}=0.046)$. Elderly $(\mathrm{p}<0.001)$ and females $(\mathrm{p}=0.034)$ were associated with CC, while most TB patients were male $(p=0.02)$ earning less than two minimum wage. Over half of the participants receive more than two minimum salaries and had at most elementary education. Body mass index was significantly lower in both TB groups $(\mathrm{p}<0.005)$. Most participants $(>89 \%)$ reported to receive city treated water for consumption and for $58.3 \%$, the municipal garbage collection was held 2 - 3 times per week

Of 111 individuals enrolled in the study, 50 (45\%) tested positive for IP, concurrent IPTB infection being 28.5\% (10/35) and 52.6\% (40/76) asymptomatic IPCC. In both IP infected groups, Endolimax nana (20/50, 40\%) and Entamoeba coli $(11 / 50,22 \%)$, followed by E. dispar $(4 / 50,8 \%)$ and Iodamoeba butschili $(1 / 50,2 \%)$, were the most protozoan nonpathogenic identified. Among IPTB co infected subjects, $40 \%$ had pathogenic species Ascaris lumbricoides, Giardia intestinalis and Strongyloides stercoralis. The IPCC individuals had pathogenic 
Table 1. Clinical, socioeconomic data on participants with or without intestinal parasite infection.

\begin{tabular}{|c|c|c|c|c|}
\hline & \multicolumn{4}{|c|}{ Number (\%) } \\
\hline & $\mathrm{TB}(\mathrm{n}=25)$ & $\operatorname{IPTB}(\mathrm{n}=10)$ & $\mathrm{CC}(\mathrm{n}=36)$ & $\operatorname{IPCC}(n=40)$ \\
\hline Age $($ mean $\pm \mathrm{SD})$ & $41.8 \pm 12.55$ & $40.3 \pm 15.83$ & $55.1 \pm 12.05^{\star * *}$ & $44.9 \pm 13.82$ \\
\hline \multicolumn{5}{|l|}{ Gender } \\
\hline Female $(n=56)$ & $8(32)$ & $5(50)$ & $23(63.9)$ & $20(50)$ \\
\hline Male $(\mathrm{n}=55)$ & $17(68)$ & $5(50)$ & $13(36.1)$ & $20(50)$ \\
\hline \multicolumn{5}{|l|}{ Smoker. } \\
\hline Positive & $5(20)$ & $5(50)^{*}$ & $8(22.2)$ & $7(17.5)$ \\
\hline Negative & $20(80)$ & $5(50)$ & $28(77.8)$ & $33(82.5)$ \\
\hline \multicolumn{5}{|l|}{ AFB smear } \\
\hline Negative & $14(66.7)$ & $5(62.5)$ & & \\
\hline Positive & $7(14.3)$ & $3(12.5)$ & & \\
\hline No Information & $4 / 25$ & $2 / 10$ & & \\
\hline \multicolumn{5}{|l|}{ TB Site of infection: } \\
\hline Pulmonary & $18(72)$ & $8(80)$ & & \\
\hline Extra pulmonary & $7(28)$ & $2(20)$ & & \\
\hline \multicolumn{5}{|l|}{ Family monthly Income (One basic salary $=$ US\$325.72) } \\
\hline$<$ one & $2(8)$ & $3(30)$ & $1(2.8)$ & $2(5)$ \\
\hline one & $8(32)$ & $3(30)$ & $14(38.9)$ & $10(25)$ \\
\hline two - four & $13(52)$ & $3(30)$ & $18(50)$ & $23(57.5)$ \\
\hline$>$ four & $2(8)$ & $1(10)$ & $3(8.3)$ & $5(12.5)$ \\
\hline \multicolumn{5}{|l|}{ Education: } \\
\hline Illiterate & $1(4)$ & $1(10)$ & $3(8.4)$ & $2(5)$ \\
\hline Incomplete elementary School & $4(16)$ & $3(30)$ & $21(58.3)$ & $15(37.5)$ \\
\hline Elementary school & $6(24)$ & $2(20)$ & $4(11.1)$ & $5(12.5)$ \\
\hline Incomplete high school & $4(16)$ & $1(10)$ & $1(2.8)$ & $4(10)$ \\
\hline High school & $9(36)$ & $2(20)$ & $7(19.4)$ & $10(25)$ \\
\hline Technical or higher & $1(4)$ & $1(10)$ & $0(0)$ & $4(10)$ \\
\hline Body Mass Index $-B M I($ mean $\pm \mathrm{SD})(\mathrm{n}=95)$ & $22.4 \pm 3.54^{* * *}$ & $22.0 \pm 3.47^{\star}$ & $27.6 \pm 5.97$ & $28.0 \pm 5.93$ \\
\hline \multicolumn{5}{|l|}{ Dwelling House: } \\
\hline Coated masonry & $15(60)^{* * *}$ & $7(70)^{* * *}$ & $35(97.2)$ & $34(85)$ \\
\hline Uncoated masonry or wood & $10(40)$ & $3(30)$ & $1(2.8)$ & $6(15)$ \\
\hline \multicolumn{5}{|l|}{ Water for consumption: } \\
\hline Public treated water & $25(100)$ & $8(80)$ & $35(97.2)$ & $36(90)$ \\
\hline Mineral or artesian well & $0(0)$ & $2(20)$ & $1(2.7)$ & $4(10)$ \\
\hline \multicolumn{5}{|l|}{ Garbage Public Collection: } \\
\hline One(time per week) & $3(12)$ & $1(10)$ & $5(13.9)$ & $2(5)$ \\
\hline Two - three (time per week) & $19(76)$ & $6(60)$ & $21(58.3)$ & $27(67.5)$ \\
\hline Daily & $2(8)$ & $1(10)$ & $8(22.2)$ & $9(22.5)$ \\
\hline$\geq$ to Fortnightly & $0(0)$ & $1(10)$ & $1(2.8)$ & $0(0)$ \\
\hline Without information & $1(4)$ & $1(10)$ & $1(2.8)$ & $2(5)$ \\
\hline
\end{tabular}

${ }^{*} \mathrm{p}<0.05 ;{ }^{* * *} \mathrm{p}<0.001$. SD: Standard Deviation. TB: tuberculosis patients; IPTB or IPCC: intestinal parasites TB co infected or asymptomatic intestinal parasitic infected community control. 
Table 2. Intestinal parasites infection data on community control individuals and tuberculosis patients.

\begin{tabular}{cccc}
\hline \multirow{2}{*}{ Species } & \multicolumn{2}{c}{ Number of infected participants (\%) } \\
\cline { 2 - 4 } & IPTB & IPCC & TOTAL \\
\hline Any parasite & $10 / 35(28.5)$ & $40 / 76(52.6)$ & $50 / 111(45)$ \\
Nonpathogenic species & $5 / 10(50)$ & $30 / 76(39.4)$ & $35 / 86(70)$ \\
Entamoeba coli & $2 / 10(20)$ & $9 / 40(22.5)$ & $11 / 50(22)$ \\
Endolimax nana & $3 / 10(30)$ & $17 / 40(42.5)$ & $20 / 50(40)$ \\
Entamoeba díspar & 0 & $4 / 40(10)$ & $4 / 50(8)$ \\
Iodamoeba butschili & $1 / 10(10)$ & & $1 / 50(2)$ \\
Pathogenic species & $4 / 10(40)$ & $20 / 76(26.3)$ & $24 / 50(48)$ \\
Ascaris lumbricoides & $2 / 10(20)$ & $1 / 40(2.5)$ & $3 / 50(6)$ \\
Giardia intestinalis & $1 / 10(10)$ & $5 / 40(12.5)$ & $6 / 50(12)$ \\
Strongyloides stercoralis & $1 / 10(10)$ & $3 / 40(7.5)$ & $4 / 50(8)$ \\
Entamoeba histolytica & 0 & $7 / 40(17.5)$ & $7 / 50(14)$ \\
Taenia sp. & 0 & $2 / 40(5)$ & $2 / 50(4)$ \\
Schistossoma mansoni & 0 & $1 / 40(2.5)$ & $1 / 50(2)$ \\
Enterobius vermicularis & 0 & $1 / 40(2.5)$ & $1 / 50(2)$ \\
Dual parasitism & 0 & $10 / 40(25)$ & - \\
\hline
\end{tabular}

IPTB or IPCC: intestinal parasites TB co infected patients and asymptomatic intestinal parasitic infected community controls.

species Entamoeba histolytica, Giardia intestinalis, Strongyloides stercoralis, Taenia $s p$. and three participants, respectively infected by Schistossoma mansoni, Ascaris lumbricoides and by Enterobius vermicularis. Dual parasitism accounted for 25\% (Table 2).

\subsection{IgE Is Increased in Asymptomatic IP Infected Participants}

All 111 participants had serum IgE tested and was significantly higher in IPCC vs $\mathrm{CC}(80.18 \pm 144.8$ vs $36.33 \pm 75.03, \mathrm{p}=0.036)$, and slightly increased in IPTB com-pared to TB $(93 \pm 132.2$ vs $57.36 \pm 78.17, \mathrm{p}=0.673)$. The IgE systemic higher level $(>300 \mathrm{UI} / \mathrm{ml})$ was associated with either nonpathogenic (E. coli and $E$. nana) or pathogenic ( $G$. intestinalis, E. histolytica) protozoa infection.

\subsection{IPTB Coinfection Did Not Influence the Production of INF- $\gamma$ Specific Antigens}

Of 108 participants tested for IFN- $\gamma$ production 36 were CC, 38 IPCC, 25 TB patients and 9 IPTB (Table 3). The IPTB exhibited a slightly lower average level of IFN- $\gamma$ compared to that $\mathrm{TB}(\mathrm{p} \geq 0.474)$ for both antigens, however, it was strongly high compared to that CC/IPCC $(\mathrm{p}<0.001)$. This tendency remained after stratifying them into infection by pathogenic versus nonpathogenic intestinal parasites (data not shown). The frequency of the positive IFN- $\gamma$ producer was similar 
in the groups, TB: $21 / 25,84 \%$ and $19 / 25,76 \%$; IPTB: $7 / 9,78 \%$ and $6 / 9,67 \%$; CC: $2 / 36,5.5 \%$ and $1 / 36,2.8 \%$; IPCC: $0 / 40$ and $1 / 40,2.5 \%$, respectively for each $38 \mathrm{kda} / \mathrm{CFP}-10$ and ESAT-6/CFP-10 antigens. Thus, IP does not affect IFN- $\gamma$ release assays based on these antigens. Only one IPCC infected with $G$. intestinalis and three CC participants exceeded IFN- $\gamma$ cut off, being one of each group induced by ESAT-6/CFP-10, but two CC also related with $38 \mathrm{kDa} / \mathrm{CFP}-10$ stimuli, possibly reflecting past Mtb infection.

\subsection{IPTB Coinfection Is Associated with Increased ESAT-6/CFP-10 Specific Production of IL-5, IL-13 and GM-CSF}

The Th type 2 cytokines IL-5 ( $\mathrm{p}=0.001)$, IL-13 ( $\mathrm{p} \leq 0.029)$ and also the pro-inflammatory chemokine GM-CSF ( $\mathrm{p} \leq 0.026$ ) exhibited significantly higher mean levels in IPTB compared to that TB and controls, stimulated with ESAT-6/ CFP-10. However, no significant difference to both antigens in the average level of IL-4 ( $\mathrm{p}>0.097$ ). Moreover, IL-5 production was significantly high in response to $38 \mathrm{kDa} / \mathrm{CFP}-10$ compared to ESAT-6/CFP-10 only in TB group ( $\mathrm{p}=0.041$ ) (Table 3).

\subsection{IPTB Coinfection Elicited Lower Specific ESAT-6/CFP-10 Production of IL-1 $\beta$}

The IPTB gave rise to a strong reduction of IL- $1 \beta$ compared to all others groups $(\mathrm{p} \leq 0.029)$, although borderline to TB $(\mathrm{p}=0.068)$. Moreover, TB $(\mathrm{p}=0.006)$ and IPCC ( $\mathrm{p}=0.029)$ showed low levels compared to CC/IPCC, all associated with ESAT-6/CFP-10. In addition, $38 \mathrm{kDa} / \mathrm{CFP}-10$ elicited higher IL- $1 \beta$ expression in all groups compared to ESAT-6/CFP-10 but significant only to TB group $(\mathrm{p}=0.029)($ Table 3$)$.

\subsection{IPTB Coinfection Did Not Show Different Specific-Antigens Production of IL-2, TNF- $\alpha$, IL-17A, IL-6, IL-10, MIP1 $\beta$ and MCP-1}

There was no significant difference to both antigens average level of Th1 (IL-2, TNF- $\alpha$ ), Th17 (IL-17A), pro-inflammatory IL-6 and regulatory IL-10 cytokines, as well as of MIP1 $\beta$ and MCP-1 chemokine, among tested groups. However, 38 $\mathrm{kDa} / \mathrm{CFP}-10$ showed higher immune regulatory cytokine (IL-10, $\mathrm{p}=0.001$ ) expression compared to ESAT-6/CFP-10 in TB and IPCC (Table 3).

\subsection{IPTB Coinfection Is Associated with Specific $38 \mathrm{kDa} / \mathrm{CFP}-10$ Production of IL-8 Chemokine}

The mean level of IL- 8 was significantly increased associated to $38 \mathrm{kDa} / \mathrm{CFP}-10$ stimuli in IPTB compared to both controls groups $(\mathrm{p}<0.049)$. However, in response to ESAT-6/CFP-10 antigen, which compared with $38 \mathrm{kDa} / \mathrm{CFP}-10$, there was a significant expression in both CC groups ( $\mathrm{p} \leq 0.035)$. On the other hand, G-CSF chemokine lower mean level related to ESAT-6/CFP-10 stimuli in IP infected groups, but significance only for IPCC compared to both IP uninfected 
Table 3. Mean cytokines levels produced by peripheral blood mononuclear cells of parasite infected or uninfected subjects.

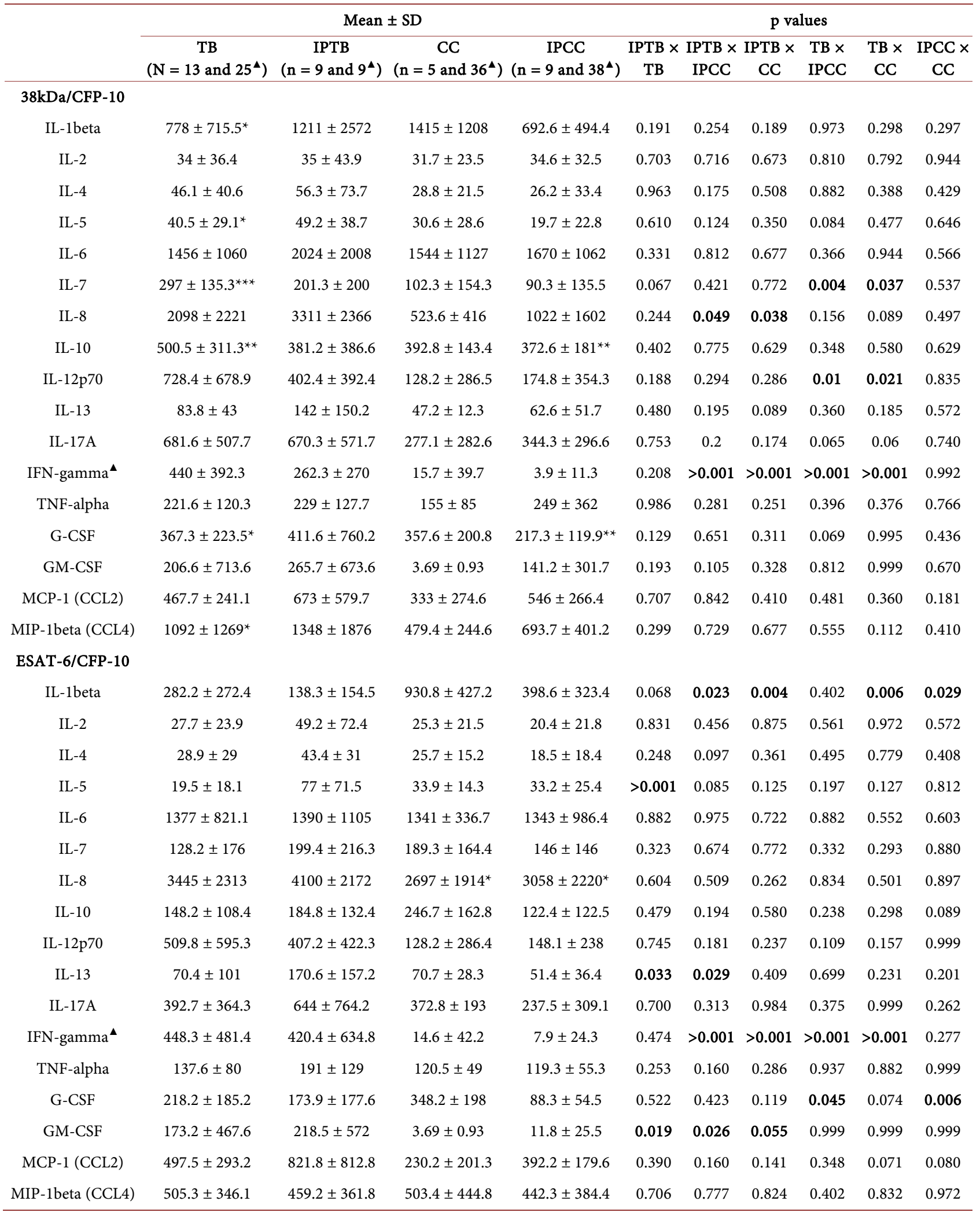

Cytokine mean results in units of $\mathrm{pg} / \mathrm{ml}$ together with standard deviation (SD). $\mathrm{N}^{\mathbf{\Lambda}}=$ Number of cases tested INF-gamma release assay. Significant difference of cytokine/chemokines production between groups and between antigen tested was calculated by Mann Whitney $\left({ }^{* *}, \mathrm{p} \leq 0.0001 ;{ }^{* *}, \mathrm{p} \leq 0.01 ;{ }^{*}, \mathrm{p} \leq\right.$ 0.05). TB: tuberculosis patients; IPTB or IPCC: TB-intestinal parasites co infected or asymptomatic IP infected community control. 
groups $(\mathrm{p} \leq 0.045)$. Higher expression of this chemokine was significant in TB and IPCC in response to $38 \mathrm{kDa} / \mathrm{CFP}-10$ compared to ESAT-6/CFP-10 stimuli (Table 3).

\subsection{TB Alone Is Associated with Specific 38 kDa/CFP-10 Production of IL-7 and IL12p70}

The regulatory cytokines IL-7 and IL12p70 were significantly high in TB subjects compared to both controls groups ( $\mathrm{p} \leq 0.037)$, but IPTB elicited slightly IL-7 lower level $(\mathrm{p}=0.067)$, all related to $38 \mathrm{kDa} / \mathrm{CFP}-10$. Moreover, $38 \mathrm{kDa} / \mathrm{CFP}-10$ elicited a significantly higher level of IL-7 than to ESAT-6/CFP-10 in TB group $(\mathrm{p}=0.008)$ (Table 3$)$.

\section{Discussion}

In the present study, $45 \%$ of the studied individuals tested positive for IP, and among TB patients $28.5 \%$ were coinfected, a similar frequency to that in other studies [6] [15]. However, prevalence $>50 \%$ has also been described [23] [24] [25]. This difference may be associated with sociodemographic characteristics of the populations studied, as recruiting only symptomatic IPTB inpatient [24]. The higher rate of parasitism in asymptomatic controls (36\%) was similar to other low-income populations in two other locations in the state of Rio de Janeiro (27.2\% and 49.7\%) [26]. However, contrary to other Brazilians findings [13], $62 \%$ of positives in our study were infected with non-pathogenic protozoa, a commensal of the human gut, thus probably related to the bad quality available drinking water, despite most participants reporting access to municipally treated water. Thus, analyzes of the local water and soil are urgent in the area.

The impact of IP infections in the suppression of the Th1 immune response, essential for protection against TB, deregulating the immune system toward the Th2 branch remains contradictory. In order to test the hypothesis that part of this variable response may be associated to specific antigens of $M$. tuberculosis, we investigated the effects of $38 \mathrm{kDa} / \mathrm{CFP}-10$ and ESAT-6/CFP-10 on Th1/Th2 patterns in intestinal parasite infected TB patients. Several studies have demonstrated a significant decrease in the production of IFN- $\gamma$ in IPTB [6] [9] [14]. However, our data reveal no significant impairment in the mean levels of this cytokine under both antigens stimuli. An increase of IFN- $\gamma$, in IPTB associated with the Th1 response in the initial stages of IP infection has been demonstrated, although only a few patients showed high levels of the cytokine [15] [27], which also was observed in the present study. Other have described a significant decrease of IL-12 and IFN- $\gamma$ in LTBI patients co infected with filaria [9], the responses associated with PPD and culture filtrate antigens to stimulate $\mathrm{T}$ cells. It is possible that lack of significance in our study may be associated with the parasites not generating a severe decrease in the Th1 response, as with the filarial infection, or for the antigens studies the IFN- $\gamma$ response is not significantly influenced by the IP infection. 
The mean levels of all cytokines were not significantly different in IPTB vs TB, mainly for $38 \mathrm{kDa} / \mathrm{CFP}-10$. However, we noted significant levels of the cytokines IL-1 $\beta$, IL-5, IL-7, IL-10 and G-CSF for this antigen comparing to ESAT-6/ CFP-10 in TB patients. Thus possibly suggesting differential modulation in TB host.

The Th2 immunity arm activates several downstream effector mechanisms that promote parasite eradication or at least minimize host tissue damage. The Th2 cytokines, such as IL-4, IL-5, IL-6, and IL-13, leading to the production of B cell, immunoglobulin IgE and IgG subtypes, eosinophilia and mast cells inhibiting parasite invasion or dissemination [28]. The significant partial Th2 cytokines expression (IL-5 and IL-13) in IPTB, associated to ESAT-6/CFP-10, is in accordance with the increased production of IgE. However, the failure in the significance related to TB could be that some TB patients harbor occult parasite infection and the study examined only a single stool sample from each participant. Notwithstanding, this may not be the case because IgE level was significantly higher in the IPCC in relation to the CC group. Another possible explanation is that IgE has also risen in active TB, decreasing with treatment [29], and here most TB patients were free of treatment with a higher average of IgE (58.8 \pm 71.6) compared to those treated $(22.5 \pm 27.6)$. However, our small sample size and/or no prevalence of pathogenic intestinal parasites such as $A$. lumbricoides, $T$. trichiuris or $S$. stercoralis as reported by others could also be associated [8]. Additionally, IPTB clearly increases partially the Th2 and pro-inflammatory GM-CSF cytokines levels (but not IL-10) associated to the ESAT-6/CFP-10 stimuli. Thus, the high production of these cytokines in IPTB may favor the enhancing susceptibility to TB infection.

Previous studies have shown the TB gravidity associated with disease progression and with a low immune response in a broad range of $\mathrm{T}$ cell to pathogens stimulation. Beside TNF- $\alpha$, it was detected lower IL- $1 \beta$ and IL-7 levels in patients with poor TB clinical evolution after dead $M$. tuberculosis cell stimulation [30] [31]. In our study, lower level of IL- $1 \beta$ was associated to ESAT-6/CFP-10, while IL-7 levels were lower but associated with $38 \mathrm{kDa} / \mathrm{CFP}-10$. Thus, IP and different antigens may impair the immune response. IL- $1 \beta$ is important for walling off infection and preventing dissemination of microbial infection being of critical importance to control $M$. tuberculosis infection. In an animal model co infected with intestinal nematodes Heligmosomoides polygyrus and subsequently Schistosoma mansoni, there was a reduction in a number of eggs and proinflammatory cytokines as well as Th1 profile, including IL-1 $\beta$ [12]. This authors suggests that presence of an intestinal parasite negatively influences IL- $1 \beta$ production, corroborating our findings. The IL-7 act upon T cell response development and in turn homeostasis, aiming to control the infection. Feske et al. [32] identified IL-7 and IL-15 associated a high IFN- $\gamma\left(\right.$ ELISPOT $\left.^{\circledR}\right)$ in response to ESAT-6/CFP10 and cytomegalovirus antigens in TB patients. In our study there wasn't any significant difference for these cytokines related to ESAT-6/ 
CFP-10, however, IPTB in response to $38 \mathrm{kDa} / \mathrm{CFP} 10$ antigen, IL-7 slightly depress, together with INF- $\gamma$, was achieved ( $p \geq 0.067$ ), suggesting that different Mtb antigens can modulate the response in the IP infected host. However, as parasite treatment was not provided we could not be sure about recover in these cytokines modulation.

The IL-8, or CXC chemokine, an important neutrophil-activating factor, provides the chemotaxis of inflammatory cells to the site of infection [1] and pretreatment with IL-8 inhibit granuloma formation. Among the pro-inflammatory cytokines assayed in our study, the IL- 8 was the only one significantly up-modulated in IPTB, although without significance as compared to TB, but associated to $38 \mathrm{kDa} / \mathrm{CFP}-10$ stimuli. Active IL- 8 may help to kill the pathogen and so initiate events that curb microorganism growth. These data suggest that increased production of IL- 8 may be associated with stimuli used and the status of co infection may favor production of this chemokine.

Neutrophils are the most numerous types of lymphocytes, and the factors involved in their differentiation are G-CSF, IL-6, GM-CSF, and IL-13, which are critical in the activation of the antibacterial neutrophils response [33] [34]. In our findings, the GM-CSF pro-inflammatory cytokine and the IL-13, together with IL-5, type Th2 cytokines were differentially express in IPTB, associated with ESAT-6/CFP-10, thus possibly suggesting differential modulation to the antigen in co infected TB host, which may play a role in either susceptibility to disease or enhanced disease severity [35]. However, helminth specific treatment must provide to evaluate the effect on immune response reversion.

This study has, as major limitations, the reduced number of IPTB, the absence of prevalent pathogenic IP species and no surveillance of the evolution of the immune response after IP-specific therapy. However, our study suggests that in addition to parasite infections, mycobacterial antigens immune responses inducer may be an extra reason for these controversies.

\section{Conclusion}

This study underlines that: i) Coincident TB-intestinal parasites did not exert a significant inhibitory effect on IgE levels, as well as in IFN- $\gamma$ production in response to either of two antigens, ii) however, cytokine profiles were partially significantly biased toward a Th2 type (IL-5 and IL-13) and a pro-inflammatory GM-CSF, and borderline lower to IL- $1 \beta$, but associated with ESAT-6/CFP-10; while IL-7 was borderline lower, and IL- 8 was significantly high related to both CC groups, with $38 \mathrm{kDa} / \mathrm{CFP}-10$. Last, further studies before and after anthelminthic treatment are needed.

\section{Acknowledgements}

We are grateful to Mitchell Raymond Lisbon for editing the manuscript and LIONEX GmbH (Braunschweig, Germany) for antigens donated. This research was supported by the Fundação de Amparo à Pesquisa do Estado do Rio de 
Janeiro (FAPERJ), the Conselho Nacional de Desenvolvimento Científico e Tecnológico (CNPq), and Oswaldo Cruz Institute (Fiocruz). The authors would like to thank to all those who participated in the study.

\section{Declarations of Interest}

The authors declare that there is no conflict of interests. The authors alone are responsible for the writing and content of the paper.

\section{References}

[1] Raja, A. (2004) Immunology of Tuberculosis. Indian Journal of Medical Research, 120, 213-232.

[2] Hotez, P.J., Brindley, P.J., Bethony, J.M., King, C.H., Pearce, E.J. and Jacobson, J. (2008) Helminth Infections: The Great Neglected Tropical Diseases. Journal of Clinical Investigation, 118, 1311-1321. https://doi.org/10.1172/JCI34261

[3] Li, X. and Zhou, X. (2013) Co-infection of Tuberculosis and Parasitic Diseases in Humans: A Systematic Review. Parasites \& Vectors, 6. https://doi.org/10.1186/1756-3305-6-79

[4] Borkow, G., Leng, Q., Weisman, Z., Stein, M., Galai, N., Kalinkovich, A. and Bentwich, Z. (2000) Chronic Immune Activation Associated with Intestinal Helminth Infections Results in Impaired Signal Transduction and Anergy. Journal of Clinical Investigation, 106, 1053-1060. https://doi.org/10.1172/JCI10182

[5] Elias, D., Wolday, D., Akuffo, H., Petros, B., Bronner, U. and Britton, S. (2001) Effect of Deworming on Human T Cell Responses to Mycobacterial Antigens in Helminth-Exposed Individuals before and after Bacille Calmette \pm GueÂrin (BCG) Vaccination. Clinical \& Experimental Immunology, 123, 219-225.

https://doi.org/10.1046/j.1365-2249.2001.01446.x

[6] Resende Co, T., Hirsch, C.S., Toossi, Z., Dietze, R. and Ribeiro-Rodrigues, R. (2007) Intestinal Helminth Co-Infection Has a Negative Impact on Both Anti-Mycobacterium tuberculosis Immunity and Clinical Response to Tuberculosis Therapy. Clinical and Experimental Immunology, 147, 45-52.

[7] Mendez-Samperio, P. (2012) Immunological Mechanisms by Which Concomitant Helminth Infections Predispose to the Development of Human Tuberculosis. The Korean Journal of Parasitology, 50, 281-286. https://doi.org/10.3347/kjp.2012.50.4.281

[8] Elias, D., Britton, S., Kassu, A. and Akuffo, H. (2007) Chronic Helminth Infections May Negatively Influence Immunity against Tuberculosis and Other Diseases of Public Health Importance. Expert Review of Anti-Infective Therapy, 5, 475-484. https://doi.org/10.1586/14787210.5.3.475

[9] Babu, S., Bhat, S., Kumar, N., Jayantasri, S., Rukmani, S., Kumaran, P., Gopi, P., Kolappan, C., Kumaraswami, V. and Nutman, T. (2009) Human Type 1 and 17 Responses in Latent Tuberculosis Are Modulated by Coincident Filarial Infection through Cytotoxic T lymphocyte Antigen-4 and Programmed Death-1. The Journal of Infectious Diseases, 200, 288-298. https://doi.org/10.1086/599797

[10] Diniz, L., Magalhães, E.F.L., Dietze, R., Pereira, F.E.L. and Ribeiro-Rodrigues, R. (2010) Presence of Intestinal Helminths Decreases T Helper Type 1 Responses in tuberculoid Leprosy Patients and May Increase the Risk for Multi-Bacillary Leprosy. Clinical \& Experimental Immunology, 161, 142-150.

https://doi.org/10.1111/j.1365-2249.2010.04164.x 
[11] Rafi, W., Ribeiro-Rodrigues, R., Ellner, J. and Salgame, P. (2012) Coinfection-Helminthes and Tuberculosis. Current Opinion in HIV and AIDS, 7, 239-244. https://doi.org/10.1097/COH.0b013e3283524dc5

[12] Bazzone, L., Smith, P., Rutitzky, L., Shainheit, M., Urban, J., Setiawan, T., Blum, A., Weinstock, J. and Stadecker, M. (2008) Coinfection with the Intestinal Nematode Heligmosomoides polygyrus Markedly Reduces Hepatic Egg-Induced Immunopathology and Proinflammatory Cytokines in Mouse Models of Severe Schistosomiasis. Infection and Immunity, 76, 5164-5172. https://doi.org/10.1128/IAI.00673-08

[13] Belkaid, Y., Piccirillo, C., Mendez, S., Shevach, E.M. and Sacks, D.L. (2002) CD4+CD25+ Regulatory T Cells Control Leishmania major Persistence and Immunity. Nature, 420, 502-507. https://doi.org/10.1038/nature01152

[14] Elias, D., Akuffo, H. and Britton, S. (2005) PPD Induced In Vitro Interferon Gamma Production Is Not a Reliable Correlate of Protection against Mycobacterium tuberculosis. Transactions of the Royal Society of Tropical Medicine and Hygiene, 99, 363-368. https://doi.org/10.1016/j.trstmh.2004.08.006

[15] Abbas, A., Murphy, K. and Sher, A. (1996) Functional Diversity of Helper T Lymphocytes. Nature, 383, 787-793. https://doi.org/10.1038/383787a0

[16] Erb, K., Trujillo, C., Fugate, M. and Moll, H. (2002) Infection with the Helminth Nippostrongylus brasiliensis Does Not Interfere with Efficient Elimination of $M y$ cobacterium bovis BCG from the Lungs of Mice. Clinical and Diagnostic Laboratory Immunology, 9, 727-730.

[17] Frantz, F., Rosada, R., Turato, W., Peres, C., Coelho-Castelo, A., Ramos, S., Aronoff, D., Silva, C. and Faccioli, L. (2007) The Immune Response to Toxocariasis Does Not Modify Susceptibility to Mycobacterium tuberculosis Infection in BALB/c Mice. The American Journal of Tropical Medicine and Hygiene, 77, 691-698.

[18] Tavares, R., Salgado, J., Moreira, V., Ferreira, M., Melo, F., Leung, J., Fonseca, L., Spallek, R., Singh, M. and Saad, M. (2007) Interferon Gamma Response to Combinations $38 \mathrm{kDa} / \mathrm{CFP}-10,38 \mathrm{kDa} / \mathrm{MPT}-64$, ESAT-6/MPT-64 and ESAT-6/CFP-10, Each Related to a Single Recombinant Protein of Mycobacterium tuberculosis in Individuals from Tuberculosis Endemic Areas. Microbiology and Immunology, 51, 289-296. https://doi.org/10.1111/j.1348-0421.2007.tb03910.x

[19] Diel, R., Loddenkemper, R. and Nienhaus, A. (2012) Predictive Value of Interferon- $\gamma$ Release Assays and Tuberculin Skin Testing for Progression from Latent TB Infection to Disease State: A meta-analysis. Chest, 142, 63-75.

https://doi.org/10.1378/chest.11-3157

[20] Araujo, L.S., Mello, F.Q., Silva, N.B.M., Leung, J.A.W., Machado, S.M.A., Sardella, I.G., Maciel, R.M. and Saad, M.H.F. (2014) Evaluation of Gamma Interferon Immune Response Elicited by the Newly Constructed PstS-1(285-374):CFP10 Fusion Protein to Detect Mycobacterium tuberculosis Infection. Clinical and Vaccine Immunology, 21, 552-560. https://doi.org/10.1128/CVI.00726-13

[21] WHO (2013) Global Tuberculosis Report 2013. World Health Organization, Geneva, 289.

[22] Lutz, A.V. (1919) O Schistosoma mansoni e Schistosomose, segundo observações, feitas no Brasil. Memórias do Instituto Oswaldo Cruz, 11, 121-25. https://doi.org/10.1590/S0074-02761919000100006

[23] Tristão-Sá, R., Ribeiro-Rodrigues, R., Johnson, L., Pereira, F.E.L. and Dietze, L. (2002) Intestinal Nematodes and Pulmonary Tuberculosis. Revista da Sociedade Brasileira de Medicina Tropical, 35, 533-535. https://doi.org/10.1590/S0037-86822002000500020 
[24] Elias, D., Mengistu, G., Akuffo, H. and Britton, S. (2006) Are Intestinal Helminths Risk Factors for Developing Active Tuberculosis? Tropical Medicine and International Health, 11, 551-558. https://doi.org/10.1111/j.1365-3156.2006.01578.x

[25] Brown, M., Miiro, G., Nkurunziza, P., Watera, C., Quigley, M., Dunne, D., Whitworth, J. and Elliott, A. (2006) Schistosoma mansoni, Nematode Infections, and Progression to Active Tuberculosis among HIV-1-Infected Ugandans. The American Journal of Tropical Medicine and Hygiene, 74, 819-825.

[26] Moraes Neto, A.H., Pereira, A.P., Alencar, M.F., Souza Jr., P.R., Dias, R.C., Fonseca, J.G., Santos, C.P. and Almeida, J.C. (2010) Prevalence of Intestinal Parasites versus Knowledge, Attitudes, and Practices of Inhabitants of Low-Income Communities of Campos dos Goytacazes, Rio de Janeiro State, Brazil. Parasitology Research, 107, 295-307. https://doi.org/10.1007/s00436-010-1861-7

[27] Du Plessis, N., Kleynhans, L., Thiart, L., Van Helden, P., Brombacher, F., Horsnell, W. and Walzl, G. (2013) Acute Helminth Infection Enhances Early Macrophage Mediated Control of Mycobacterial Infection. Mucosal Immunology, 6, 931-941. https://doi.org/10.1038/mi.2012.131

[28] Wang, L., Cao, Y. and Shi, H.N. (2008) Helminth Infections and Intestinal Inflammation. World Journal of Gastroenterology, 14, 5125-5132. https://doi.org/10.3748/wjg.14.5125

[29] Adams, J., Scholvinck, E., Gie, R., Potter, P., Beyers, N. and Beyers, A. (1999) Decline in Total Serum IgE after Treatment for Tuberculosis. Lancet, 353, 2030-2033. https://doi.org/10.1016/S0140-6736(98)08510-9

[30] Waitt, C.J., Peter, K.B.N., White, S.A., Kampmann, B., Kumwenda, J., Heyderman, R.S., Pirmohamed, M. and Squire, S.B. (2011) Early Deaths during Tuberculosis Treatment Are Associated with Depressed Innate Responses, Bacterial Infection, and tuberculosis Progression. The Journal of Infectious Diseases, 204, 358-362. https://doi.org/10.1093/infdis/jir265

[31] Waitt, C.J., Banda, P., Glennie, S., Kampmann, B., Squire, S.B., Pirmohamed, M. and Heyderman, R.S. (2015) Monocyte Unresponsiveness and Impaired IL1 $\beta$, TNF $\alpha$ and IL7 Production Are Associated with a Poor Outcome in Malawian Adults with Pulmonary Tuberculosis. BMC Infectious Diseases, 15, 513. https://doi.org/10.1186/s12879-015-1274-4

[32] Feske, M., Nudelman, R., Medina, M., Lew, J., Singh, M., Couturier, J., Graviss, E. and Lewis, D. (2008) Enhancement of Human Antigen-Specific Memory T-Cell Responses by Interleukin-7 May Improve Accuracy in Diagnosing Tuberculosis. Clinical and Vaccine Immunology, 15, 1616-1622. https://doi.org/10.1128/CVI.00185-08

[33] Santiago, E., Mora, L., Bautista, M., Montesinos, J.J., Martinez, I., Ramos, G., Zambrano, I.R., Manrique, B. and Weiss-Steider, B. (2001) Granulocyte Colony-Stimulating Factor Induces Neutrophils to Secrete Macrophage Colony-Stimulating Factor. Cytokine, 15, 299-304.

https://doi.org/10.1006/cyto.2001.0937

[34] Boneberg, E. and Hartung, T. (2002) Molecular Aspects of Anti-Inflammatory Action of G-CSF. Inflammation Research, 51, 119-128. https://doi.org/10.1007/PL00000283

[35] Rook, G.A. (2007) Th2 Cytokines in Susceptibility to Tuberculosis. Current Molecular Medicine, 7, 327-337. https://doi.org/10.2174/156652407780598557 